
consequences of functional diversity in paleoclimate estimation using fossil wood

${ }^{1}$ Museo Paleontológico de Múzquiz, Adolfo E. Romo 1701, La Cascada, 26343, Santa Rosa de Múzquiz, Melchor Múzquiz, Coahuila, Mexico Nacional, Prolongación de Carpio y Plan de Ayala s/n, 11340 Ciudad de México, México

\title{
17 ABSTRACT
}

18 Community assembly processes, environmental filtering and limiting similarity, determine

19 functional traits values within communities. Because environment influences the number of

20 viable functional strategies species might take, a strong effect of environmental filter often results

21 in communities having species with similar trait values and narrow functional niches. On the

22 other hand, limiting similarity lead to communities with broader functional spaces. The degree to

23 community assembly processes influence wood trait variation has important implications for 
24 paleoclimate estimation using fossil wood since the main tenet of the approach is environmental

25 driven trait convergence, and assumes a central role of environmental filtering. We used

26 functional diversity (FD) to determine how three wood anatomical traits vary in 14 extant

27 communities (272 species) growing under different climate regimes, and inferred the prevalence

28 of environmental filtering/limiting similarity. We also calculated FD metrics for the El Cien

29 Formation fossil woods and discussed the results in light of the current knowledge of the flora.

30 We found lower anatomical diversity in communities growing in dry/cool places (smaller

31 functional spaces and lower abundance of trait combinations), suggesting that strong wood

32 anatomical trait convergence could be the result of stronger habitat filtering in these communities.

33 A lower strength of environmental filter in warm/wet environments, likely results in an

34 amplification of the role of other drivers that promote higher number of hydraulic strategies

35 through niche partition in highly structured communities. More complex ecological structures in

36 mild tropical places likely lead to a higher spread of wood trait values. This asymmetry in the

37 strength of environmental filter along climate gradients, suggest that the imbalances in strength of

38 the trait-climate convergence, should be incorporated in paleoclimate prediction models. FD

39 approach can be used to recognize promising traits with narrow niches along climate gradients,

40 and therefore a constant effect of environmental filter.

42 Keywords: fossil wood; functional diversity, paleoclimate, paleoecology, wood anatomy 


\section{INTRODUCTION}

49 Limited distribution of species in relation to environment is explained by community assembly

50 hypothesis throughout a series of processes occurring at local scale that allow some species, but

51 not others, to coexist (Diamond 1975; Cornwell and Ackerly 2009). These community assembly

52 processes (i.e. environmental filtering and limiting similarity) determine functional trait values

53 within communities (Weiher et al. 1998; Grime 2006; Cornwell and Ackerly 2009). While

54 environmental filter sets limits to the range of ecological strategies and trait values that species

55 might take in particular sites (Weiher and Keddy 1995; Diaz et al. 1998; Cornwell and Ackerly

56 2009), limiting similarity (particularly competition) constraints the degree of trait similarity

57 among species (MacArthur and Levins 1967). That is, while environmental filter tends to drive

58 trait to a particular value, limiting similarity tends to constrain the degree of trait similarity

59 among species within communities. Environmental filtering occurs when there is high selection

60 pressure on traits. It occurs, for example, when species with very low resistance to drought-

61 induced embolism are excluded from places experiencing drought, resulting in communities with

62 highly convergent trait values conferring cavitation resistance. Limiting similarity occurs when

63 there is a great overlap in niche requirements among species, resulting in competition and local

64 exclusion from a given community. Alternatively, limiting similarity might lead to species

65 coexistence if there is resource partition or results in segregation in different microsites (Chesson

66 2000). When resource partition is strong, it might be expected an even spacing of trait values in a

67 given community (Cornwell and Ackerly 2009). This resource partition is present, for example,

68 among species in vertically structured communities, where short shade-tolerant species of the

69 understory species tend to be mechanically stronger (Puntz and Brokaw 1989) and higher wood

70 density (van Gelder et al. 2006) than larger light demanding species (Puntz and Brokaw 1989;

71 Falster and Westoby 2005). Along this light gradient, wood anatomical varies with the vertical 
72 niche position because vessel size and density are related to plant size (e.g. Preston et al. 2006) to

73 cope with conduction demands associated with increasing height (Ryan and Yoder 1997).

74 Paleoclimate estimation using fossil wood anatomical traits has largely focused on the

75 effect of the environmental filter on trait values to make predictions (e.g. Weimann et al. 1998,

76 1999; Martínez-Cabrera and Cevallos-Ferriz 2008). This approach essentially focuses on the

77 strength of environmental filter as it measures the degree of climate convergence of trait values to

78 build their climate prediction models. These models use the relative prevalence of a qualitative

79 trait and/or the difference in trait values under different environments. Limiting similarity,

80 however, might have important consequences in the context of paleoclimate estimation since the

81 possibilities of values a trait might take would increase due to a higher niche diversity in more

82 structured communities, hindering the effect of environmental convergence. That is, while

83 environmental filtering selects for trait convergence (Keddy 1992), species interaction and

84 limiting similarity might have a diversifying effect on trait values (Losos 2008) to allow partition

85 of resources and occupation of a variety of niches. The strength of these two community

86 assembly processes might differ by trait and climate regime, likely having an effect on predictive

87 models of paleoclimate estimation. As a consequence, it would be harder to draw paleoclimatic

88 predictions on highly structured communities compared to those where environmental filter is

89 stronger. It is possible that the prediction models using wood anatomy that have been derived so

90 far have confounding effects since they use traits on which the relative strength of environmental

91 filtering and limiting similarity is still unknown.

92 In this study, we use a functional diversity framework to determine how wood anatomical trait

93 variation patterns differ in extant communities in relation to the climate they occupy. We

94 particularly focused on hydraulic traits. We tested if communities from mild wet tropical

95 environments have a narrow hydraulic niche variation, which would suggest strong effect 
96 environmental filter, or if, on the other hand, despite water availability in these places, the water

97 conduction morphospace is large due to more structured communities in the tropics (stronger

98 effect of limiting similarity). As the functional diversity approach might shed light on the relative

99 strength of the community assembly forces, and ultimately on the general environment, we

100 applied the same framework to describe the different aspects of wood functional trait diversity of

101 El Cien Formation flora to contrast the new evidence with the current ideas of the ecological

102 characteristics of the paleoflora (Martínez-Cabrera and Cevallos-Ferriz 2008; Martinez-Cabrera

103 et al. 2012).

104

105 MATERIAL AND METHODS

106 We used a previously compiled a dataset of vessel traits from 272 species across 14 communities

107 (Martínez-Cabrera and Cevallos-Ferriz 2008; Schenk et al. 2008; Martínez -Cabrera et al. 2009,

108 2011, 2018). These plant communities range from tropical rainforest (from Mexico, Brazil and

109 Suriname) to communities with drier climate such as desert vegetation (from southern USA,

110 Mexico and Argentina) and temperate forest (USA) (Table 1).

111 Vessel lumen diameter was measured on at least 25 random measurements in the tropical

112 communities (Martínez-Cabrera and Cevallos-Ferriz 2008; Martínez-Cabrera et al. 2011). In the

113 communities described in Schenk et al. (2008) and Martínez-Cabrera et al. (2009, 2011), mostly

114 from dry or temperate areas, these traits were measured on 100 to 200 cells. We calculated

115 potential conductivity per stem cross sectional area $\left(K_{s}\right)$ following Zanne et al. (2010):

$116 K_{s} \propto F^{1.5} S^{0.5}$ were $F$ is the vessel fraction and $S$ is a vessel size contribution metric. Vessel

117 fraction $F$ is mean vessel area $\bar{A}$ times vessel density $(N)\left(\boldsymbol{F}=\bar{A}^{*} \boldsymbol{N} ; \mathrm{mm}^{2} \cdot \mathrm{mm}^{-2}\right)$, and $S$ is the

118 ratio of the same anatomical traits $\left(S=\bar{A} / N ; \mathrm{mm}^{4}\right) . \bar{A}$ is the mean individual vessel cross 
119 sectional area and $N$ is the vessel number per unit of sapwood area (Zanne et al. 2010). $\bar{A}$ was

120 calculated using mean vessel diameter. $F$ is inversely related to mechanical strength (Preston et

121 al. 2006; Zanne et al. 2010), while $S$ is directly correlate to a increased cavitation risk that is

122 coupled to high water conduction capacity (Zanne et al. 2010). $F$ and $S$ represent different axes of

123 variation as they are orthogonal (Zanne et al. 2010).

Climate information, mean annual temperature (MAT), mean annual precipitation (MAP),

125 annual potential evapotranspiration (PET) and aridity index (AI= MAP/PET; aridity index

126 mirrors precipitation, so higher AI is observed in places with high MAP), was obtained from

127 weather stations located in close proximity to the studied localities. For the Mexican montane and

128 tropical rainforest communities we used the ERIC (Extractor Rápido de Información

129 Climatológica) database (INTA 2000). We used the historical records of the weather station at the

130 Biological Station of Chamela (UNAM) to obtain climate information from the Mexican tropical

131 deciduous forest. The climate variables from the Brazilian tropical rainforests communities

132 (Manaus and Porto Velho) were calculated from historical information of a 30-year period

133 (Instituto Nacional do Meteorología, Brazil). For the drier sites in Schenk et al. (2008) and

134 Martínez-Cabrera et al. (2009), climate data was obtained from the nearest weather station with

135 long-term (30-year) climate data.

\section{$137 \quad$ Functional diversity metrics}

138 We calculated several complementary functional diversity indices using the vessel traits

139 mentioned above $\left(K_{s}, S\right.$ and $\left.F\right)$. Functional richness (FRic), functional dispersion (FDis),

140 functional eveness (FEve). FRic measures the amount functional space filled by a community

141 (Villéger et al. 2008), it is the volume in n-dimensional space occupied by species in 
142 communities, where $\mathrm{n}$ represents the number of traits. In this case, it is the volume occupied by

143 the species in each community in the three dimensions of the measured traits $\left(K_{s}, S\right.$ and $\left.F\right)$. We

144 used FRic to determine if the size of the functional space increases, or decreases, with particular

145 climate variables and thus infer if community trait convergence/divergence patterns are related to

146 climate. FDis computes the average distance in trait space of individual species to their group

147 centroid and it is independent of species richness (Laliberté and Legendre 2010). FDis gives

148 information about changes in abundance of trait combinations (Laliberté and Legendre 2009).

149 FEve measures the regularity of spacing between species along functional trait gradients and it is

150 independent of species richness. FEve is 1 when the distances between all nearest neighbor

151 species pairs are identical (Villéger et al. 2008).

152 We calculated FRic, FDis and FEve using the dbFD function of the FD package (Laliberté et al.

153 2014) in $\mathrm{R}$ ( $\mathrm{R}$ Core Team 2019). In addition, we used convex hull volumes to visualize the

154 multidimensional trait space of each community. The convex hull is the minimum convex hull

155 that includes all the species in each community. The convex hulls are built by selecting the

156 extreme values for each trait, representing the vertices, to then link them and calculate the

157 volume. The convex hull volume was calculated using the Quickhull algorithm (Barber at al.

158 1996) as implemented the R package geometry (Roussel et al. 2019).

159

\section{El Cien Formation}

161 The El Cien Formation sediments are exposed in the southern part of the Baja California

162 Peninsula (Applegate, 1986), approximately $100 \mathrm{~km}$ northwest of La Paz. The fossil woods,

163 preserved as silica permineralizations, were collected in upper member of the formation (Cerro

164 Colorado Member), near Rancho Matanzas, and Cañada El Canelo, about 5 km northeast and 3.5

$165 \mathrm{~km}$ southwest from the El Cien, respectively (Fig. 1). The El Cien Formation is a clastic 
166 sedimentary sequence deposited during the late Oligocene-early Miocene (Applegate 1986;

167 Fischer et al. 1995). The sediments of the member where the fossil woods were found are mainly

168 composed of fine- to coarse-grained sandstones, tuffaceous sandstones and conglomerates

169 (Applegate 1986; Gidde 1992; Fischer et al. 1995). The current wood diversity of the El Cien

170 Formation is 21 morphotypes, all of them were used for these analyses (Martínez-Cabrera and

171 Cevallos-Ferriz 2008). The samples studied here are housed in National Paleontological

172 Collection, Institute of Geology, Universidad Nacional Autónoma de Mexico (UNAM), Mexico.

173

174 RESULTS AND DISCUSSION

175 Functional richness (FRic), the amount of functional space occupied by species in a community is

176 positively related with MAP $\left(r^{2}=0.51, p=0.003\right.$; Fig. $\left.2 A\right), A I\left(r^{2}=0.40, p=0.014 ;\right.$ Fig. $\left.2 B\right)$ and

177 MAT $\left(\mathrm{r}^{2}=0.39, \mathrm{p}=0.015\right.$; Fig. 2C). Therefore, communities in places with higher precipitation,

178 temperature and lower aridity (higher values indicate low aridity) are functional richer (i.e. larger

179 hydraulic niche) than in dry/cold places, where functional convergence results in a more

180 restricted hydraulic niche (Fig. 3A). Functional dispersion (FDis), the overall distance between

181 individual species form the center of the multivariate space, also increases with precipitation $\left(\mathrm{r}^{2}\right.$

$182=0.52, p=0.003$; Fig. 2D), AI $\left(r^{2}=0.47, p=0.006\right.$; Fig. $\left.2 \mathrm{E}\right)$ and temperature $\left(r^{2}=0.35, p=0.02 ;\right.$ Fig.

$1832 \mathrm{~F}$ ) indicating that in comparatively colder/ dryer communities trait combinations tend to be more

184 similar among species (there is a lower abundance of trait combinations, Fig. 3B). The regularity

185 of spacing among species (FEve) is not significantly related to any climate variable. PET was not

186 correlated with any of the functional diversity metrics. These results indicate that with higher

187 precipitation, coupled with higher temperature and lower aridity, the hydraulic niche and number

188 of trait combinations is larger than in dry/cool places, suggesting that functional trait convergence

189 is promoted by a stronger effect of the environmental filtering under these climates. However, 
190 communities in warm climates might have large hydraulic niches even at relatively low

191 precipitation values (e.g. semi-deciduous forest, Chamela Fig. 4A), while cool temperate

192 communities might have small hydraulic niches even if precipitation is high (hardwood forest,

193 Coweeta, Figs 4A and B). Narrow niches are often associated with a strong habitat filter (e.g.,

194 Craven et al. 2018), as it reduces the viable functional strategies of species to face particular

195 environmental pressures (Keddy 1992; Weiher and Keddy 1998). On the other hand, the

196 diversified hydraulic strategies in wet and warm environments might be the result of an increased

197 role of limiting similarity and niche partition, in part because of the relaxation of the abiotic

198 filtering. It is important to mention that limiting similarity and environmental filtering are not

199 competing models of community assembly, as both operate at the same time in a community

200 (Cornwell and Ackely 2009). Cornwell and Ackely (2009) found, evidence of both community

201 assembly processes drive variation on different traits, and in one case (specific leaf area), the

202 effect was simultaneous, with environmental filtering driving mean values along the gradient and

203 intra-community trait value spacing mediated by limiting similarity. Moreover, the relative

204 strength of these two assembly forces could shift in time and with successional position. Craven

205 et al. (2018), for example, found evidence of a greater functional convergence (lower FDis and

206 FRic) in later stages of succession in a seasonally wet tropical secondary forest.

207 The results from the convex hull volumes support the functional diversity analyses (Fig.

208 5). Overall, the volumes of convex hulls of the communities with a wet warmer climate were

209 larger and more complex when compared to those growing in dry/cool habitats (Fig. 5),

210 indicating a higher convergence of hydraulic strategies in the later communities. A more limited

211 multivariate trait space is consistent with strong abiotic filter (Keddy 1992; Cornwell et al. 2006)

212 in these sites (Fig. 5). 


\section{Implications of functional diversity paleoclimate estimation}

215 Predictive paleoclimate models using fossil wood employ trait information of extant communities

216 to build their models. These models assume that environmental trait convergence is constant

217 across communities, and therefore a constant strength of trait-climate convergence. The effect of

218 environmental filtering may, however, limit trait values more strongly in the stressful side of a

219 climate gradient, making these models good predictors on one side of a particular climate

220 gradient, but not on the opposite. In addition, if models were built using communities where the

221 effect of environmental filtering and limiting similarity/niche partition differs, the predictions

222 might have large associated errors. For example, in alpine or boreal forest small vessels are

223 strongly selected as they confer resistance against freezing induced cavitation (e.g., Davis et al.

224 1999), but on the warmer side of the gradient, temperature selection of vessel size is relaxed,

225 allowing vessel size variation to be driven by water availability (e.g., Hacke et al. 2000), canopy

226 position and succession (e.g., Apgaua et al. 2017), and overall ecological strategy (fast vs. slow

227 growing species; e.g. Apgaua et al. 2017). That is, on one side temperature strongly drives vessel

228 size (small functional niches driven by a strong filter), while on the other the temperature

229 selection on size is relaxed, allowing for larger vessels variation. These results evidenced an

230 asymmetry in the effect of environmental filter on the hydaulic strategies, with smaller hydraulic

231 niches and a lower number of trait combinations in the colder/dryer side of the spectrum, while

232 larger niches are found in the warm/wet side.

233 Functional diversity analyses can help in paleoclimate estimation by recognizing

234 individual wood traits or multi-trait axes that have narrow variation along particular

235 environmental gradients, where trait convergence operates along the gradient. This approach

236 would also provide additional information on the ecological forces driving trait variation working

237 in paleocommunities. 
239 Potential of functional diversity in studies of wood anatomical evolution

240 Evidence suggests that the relationship between wood anatomical traits and climate has not been

241 constant in the history of angiosperms, as some ecologically informative wood traits only

242 appeared in the fossil record until the Paleogene (Wheeler and Bass 1991, 2018). In addition,

243 early in the Cretaceous, there seems to be a low anatomical diversity of angiosperm woods (e.g.,

244 Wheeler and Lehman 2009; Martínez-Cabrera et al. 2017) relative to the diversity of other organs

245 (e.g., Crane and Lidgard 1989). During the early Cretaceous (Aptian-Albian) two main fossil

246 wood types dominated the assemblages (Paraphyllanthoxylon and Icacinoxylon/Platanoxylon e.g.

247 Thayn et al. 1983; Herendeen et al. 1991; Wheeler and Lehman 2009). It is only towards the

248 Cenomanian that there is a relative increase in the frequency of angiosperm fossil woods with a

249 parallel increase of anatomical diversity (Phillipe et al. 2008). Even during the Turonian-

250 Santonian there had been described, only 50 wood types in 2009 (Wheeler and Lehman 2009;

251 Chin et al. 2019). This paucity in angiosperm woods from the early Cretaceous is thought to be

252 the result of preservation (Phillipe et al. 2008), because of the prevalence of thin walls, that was

253 the partial result of the narrow ecological niche they occupied (short plants living in wet,

254 disturbed areas, e.g. Wing and Boucher 1998). Therefore, an integrated approach using

255 phylogenetic and functional diversity methods could inform us if this historical pattern is indeed

256 the results of the environment restricting niche occupancy by imposing a strong filter on traits

257 values and if the subsequent niche diversification, and the increase in morphological disparity

258 (increased divergent evolution among closely related species Martinez-Cabrera et al. 2017) was

259 coupled with an increase in the overall size of the functional landscape or through divergences of

260 closely related species occupying narrow niches. 


\section{Functional diversity of El Cien Formation}

263 The functional space occupied by El Cien Formation woods was among the larger in the

264 communities analyzed here (Fig. 2A). It was only behind the tropical rain forest from Los Tuxtlas

265 and the semi-deciduous forest from Chamela. Surprisingly, the abundance of trait combinations

266 (FDis, Fig. 2B) of El Cien Formation paleocommunity was the largest and similar to floras

267 growing under warmer and humid environments. The hydraulic niche of El Cien flora was large

268 (Fig. 3A, 5). This indicates that the flora had la large hydraulic niche, probably due to the

269 combined effects of a low strength of the environmental filter and a strong effect of limiting

270 similarity that promoted niche partition and a diversified array of strategies. This supports the

271 hypothesis of El Cien Formation flora growing under wet and warm environment. Paleoclimate

272 estimates for El Cien based on wood traits suggest a MAT of 22.5 to 24.8. The evidence

273 regarding water availability is still equivocal. Vessel characteristics indicate that the paleoflora

274 had a hydraulic capacity similar to that observed in some Mexican and South American wet

275 forests (Martínez-Cabrera and Cevallos-Ferriz 2008), suggesting a relatively wet, tropical

276 environment. However, the relatively high prevalence of ring and semi-ring porous woods

277 (Martínez-Cabrera and Cevallos-Ferriz 2008) supports the hypothesis of El Cien paleoflora

278 represents a dryer tropical deciduous or semi-deciduous forest. $40 \%$ of the nearest living relatives

279 of from El Cien paleoflora are evergreen, while $20 \%$ are deciduous. There is also a close

280 compositional similarity, since about half of the nearest living relatives of the fossils from El

281 Cien are found in the deciduous forest from southwestern coasts of Mexico (Martínez-Cabrera

282 and Cevallos-Ferriz 2008) and the two most diverse families in Chamela (Lott and Atkinson

283 2002), and the El Cien paleoflora (Martínez-Cabrera and Cevallos-Ferriz 2008) are Leguminosae

284 and Euphorbiaceae (Martínez-Cabrera et al. 2006; Martínez-Cabrera and Cevallos-Ferriz 2008).

285 Further evidence of the similarity between El Cien Formation flora and the deciduous forests of 
286 the Mexican western coast is the close estimated value of the paleoflora wood density (Martinez-

287 Cabrera et al. 2012), which is a key trait related to many ecological features including life history

288 strategies, physiological and mechanical traits (e.g., van Gelden et al. 2006; King et al. 2006;

289 Chave et al. 2009).

290 The functional diversity analyses presented here rather than inform us on the magnitude of

291 a particular climate variable in fossil flora, they provide hints on the particular assembly

292 processes driving their trait variation. The hydraulic diversity of El Cien was large, likely

293 indicating a highly structured niche and therefore prominent role of limiting similarity. In general,

294 higher environmental stress limits trait variation (e.g. wood density, Swenson and Enquist 2007),

295 so that the stronger the environmental limitations the higher the trait convergence. As in milder

296 environments this restriction to trait variation is relaxed, larger functional diversity is observed as

297 a consequence of niche partition in highly structured communities (Muller-Landau 2004).

\section{CONCLUSIONS}

300 Communities in wet/warm climates in general had higher hydraulic diversity than communities

301 growing in dry/cool environments indicating the presence of a strong environmental filter on

302 water conduction cells in the latter environments. In warmer/ wetter environments strong

303 selection of small sized vessel is relaxed and higher functional diversity is observed, likely due to

304 niche partition present in more structurally complex communities. Our results suggest that more

305 complex ecological structures in mild tropical places possibly lead to a higher spread of wood

306 trait values, making climate prediction using fossil wood more difficult in these biomes. It is

307 necessary to incorporate the effect of asymmetrical environmental convergence in paleoclimate

308 estimation models that use wood anatomical information. Functional diversity could be used to

309 identify traits with constant environmental convergence along climate gradients. 


\section{ACKNOWLEDMENTS}

312 We thank Deborah Woodcock for her comments on a previous version of the manuscript.

\section{REFERENCES}

316 Apgaua, DM, Tng DY, Cernusak LA, Cheesman AW, Santos RM, Edwards WJ, Laurance SG. 2017. Plant functional groups within a tropical forest exhibit different wood functional anatomy. Funct. Ecol. 31: 582--591.

Applegate SP. 1986. The El Cien Formation, strata of Oligocene and early Miocene age in Baja Mexico 6: 145--162.

Barber CB, Dobkin DP, Huhdanpaa HT. 1996. The Quickhull algorithm for convex hulls. ACM Transactions on Mathematical Software 22: 469--483.

324 Chin K, Estrada-Ruiz E, Wheeler EA, Upchurch, GR, Wolfe DG. 2019. Early angiosperm woods from the mid-Cretaceous (Turonian) of New Mexico, USA: Paraphyllanthoxylon, two new taxa, and unusual preservation. Cretaceous Research 261: 292--304.

327 Chesson PL. 2000. Mechanism of maintenance of species diversity. Annu. Rev. Ecol. Systemat. 3: 343--366.

329 Chave J, Andalo C, Brown S, Cairns MA, Chambers JQ, Eamus D, Fölster H, Fromard F, 330 Higuchi N, Kira T, Lescure JP, Nelson BW, Ogawa H, Puig H, Riéra B, Yamakura T. 331 2005. Tree allometry and improved estimation of carbon stocks and balance in tropical 332 forests. Oecologia 145: 87--99. 
333 Cornwell WK, Schwilk DW, Ackerly DD. 2006. A Trait based test for habitat filtering: convex

334 hull volume. Ecology 87: 1465--1471.

335 Cornwell WK, DD Ackerly. 2009. Community assembly and shifts in plant trait distributions

336 across an environmental gradient in coastal California. Ecol. Monogr. 79: 109--126.

337 Crane PR, Lidgard S. 1989. Angiosperm diversification and paleolatitudinal gradients in

338 Cretaceous floristic diversity. Science 246: 675--678.

339 Craven D, Hall JS, Berlyn GP, Ashton MS, Van Breugel M. 2017. Environmental filtering limits

340 functional diversity during succession in a seasonally wet tropical secondary forest. J.

$341 \quad$ Veg. Sci. 29: 511--520.

342 Davis SD, Sperry JS, Hacke UG. 1999. The relationship between xylem conduit diameter and cavitation caused by freezing. Am. J. Bot. 86: 1367--1372.

344 Diamond JM. 1975. Assembly of species communities. Pages 342-444 in ML Cody, JM

345 Diamond eds. Ecology and evolution of communities. Harvard University Press,

$346 \quad$ Cambridge, Massachusetts, USA.

347 Diaz S, Cabido M, Casanoves F. 1998. Plant functional traits and environmental filters at a $348 \quad$ regional scale. J. Veg. Sci. 9: 113--122.

349 Falster DS, Westoby M. 2005. Alternative height strategies among 45 dicot rain forest species 350 from tropical Queensland. Aust. J. Ecol. 93: 521--535.

351 Fischer R, Glli-Olivier C, Gidde A, Schwennicke T. 1995. The El Cien Formation of southern Baja California, Mexico: stratigraphic precisions. Newsl. Stratigr. 32: 137--161.

353 Freschet GT, Dias AT, Ackerly DD, Aerts R, van Bodegom PM, Cornwell WK, Dong M, 354 Kurokawa H, Liu G, Onipchenko VG, Ordoñez JC, Peltzer DA, Richardson SJ, Shidakov 355 II, Soudzilovskaia NA, Tao J, Cornelissen JH. 2011. Global to community scale 
differences in the prevalence of convergent over divergent leaf trait distributions in plant assemblages. Glob. Ecol. Biogeogr. 20: 755--765.

358 Grime JP. 2006. Trait convergence and trait divergence in herbaceous plant communities: mechanisms and consequences. J. Veget. Sci. 17: 255--260.

360 Gidde A. 1992. Sedimentology of the Miocene Cerro Colorado Member (upper part of the El 361 Cien Formation in Baja California Sur, Mexico). Zbl. Geol. Palaont. 6 (Teil I): 1467-$362 \quad 1477$.

363 Hacke UG, Sperry JS, Pittermann J. 2000. Drought experience and cavitation resistance in six 364 shrubs from the Great Basin, Utah. Basic and Applied Ecology 1: 31--41.

365 Herendeen PS. 1991. Lauraceous wood fromthemid-Cretaceous Potomac group of eastern North America: Paraphyllanthoxylon marylandense sp. nov. Rev. Palaeobot. Palynol. 69: 277-290.

INTA 2000. Extractor rápido de información climatológica. Instituto Nacional de Tecnología del Veg. Sci. 3:157--164.

372 King DA, Davies SJ, Tan S, Nur Supardi MN. 2006. The role of stem density and stem support cost in the growth and mortality of tropical trees. J. Ecol. 94: 670--680.

374 Laliberté E, Legendre P, Shipley B. 2014. FD: measuring functional diversity from multiple traits, and other tools for functional ecology. R package version 1.0-12.

376 Laliberté E, Legendre P. 2010. A distance-based framework for measuring functional diversity from multiple traits. Ecology 91: 299--305.

378 Losos JB. 2008. Phylogenetic niche conservatism, phylogenetic signal and the Relationship 

Letters 11: 995-1007. 83-97 In FN Noguera, JH Vega Rivera, AN García Alderete, M Quesada Avendaño, eds. Historia Natural de Chamela. Inst. Biol., Universidad Nacional Autónoma de México,

MacArthur R, Levins R. 1967. The limiting similarity, convergence, and divergence of coexisting species. American Naturalist 101: 377--385.

Martínez-Cabrera HI, Cevallos-Ferriz SRS, Poole I. 2006. Fossil woods from early Miocene sediments of the El Cien Formation, Baja California Sur, Mexico. Rev. Palaeobot. Palyno. 138: 141--163.

Martínez-Cabrera HI, Cevallos-Ferriz SRS. 2008. Palaeoecology of the Miocene El Cien Formation (Mexico) as determined from wood anatomical characters. Rev. Palaeobot. shrubs: responses to varying aridity along transcontinental transects. Am. J. Bot. 96: Palyno. 150: 154--167. trait, wood traits and height in angiosperm shrubs and trees. Am. J. Bot. 98: 915--922. 
401 Martínez-Cabrera HI, Zheng J, Estrada-Ruiz E. 2017. Wood functional disparity lags behind

402 taxonomic diversification in angiosperms. Rev. Palaeobot. Palyno. 246: 251-257.

403 Martínez-Cabrera HI, Estrada-Ruiz E. 2018 Influence of phylogenetic relatedness on

404 paleoclimate estimation using fossil wood: Vessel and fiber-related traits. Rev. Palaeobot.

$405 \quad$ Palyno. 251: 73-77.

406 Muller-Landau HC. 2004. Interspecific and intersite variation in wood specific gravity of tropical

$407 \quad$ trees. Biotropica 36: 20--32.

408 Philippe M, Gomez B, Girard V, Coiffard C, Daviero-Gomez V, Thevenard F, Billon-Bruyat J-P,

409 Guiomar M, Latil J-L, Le loeuff J, Néraudeau D, Olivero D, Schlögl J. 2008. Woody or

410 not woody? Evidence for early angiosperm habit from the Early Cretaceous fossil wood

411 record of Europe. Palaeoworld 17: 142--152.

412 Preston KA, Cornwell WK, DeNoyer JL. 2006. Wood density and vessel traits as distinct

413 correlates of ecological strategy in 51 California coast range angiosperms. New

$414 \quad$ Phytologist 170: 807--818.

415 Putz FE, Brokaw NVL. 1989 Sprouting of broken trees on Barro Colorado Island, Panama.

$416 \quad$ Ecology 70: 508--512.

417 R Core Team. 2019. R: A language and environmetn for statistical computing. R Foundation for

418 Statistical Computing, Viena, Austria. URL http://www.R-project.org/.

419 Roussel JR, Barber CB, Habel K, Grasman R, Gramacy RB, Mozharovskyi P, Sterratt DC. 2019.

$420 \quad$ Package Geometry.

421 Ryan GM, Yoder BJ. 1997. Hydraulic limits to tree height and tree growth. BioScience 47: 235-$422 \quad 242$. 
423

424

425

426

427

428

429

430

431

432

433

434

435

436

437

438

439

440

441

442

Schenk HJ, Espino S, Goedhart CM, Nordenstahl M, Martínez-Cabrera HI, Jones CS. 2008.

Hydraulic integration and shrub growth form linked across continental aridity gradients. Proc. Natl. Acad. Sci. 105: 11248-11253.

Swenson NG, Enquist BJ. 2007. Ecological and evolutionary determinants of a key plant functional trait: wood density and its community wide variation across latitude and elevation. Am. J. Bot. 94: 451--459.

Thayn GF, Tidwell WD, Stokes WL. 1983. Flora of the Lower Cretaceous Cedar Mountain Formation of Utah and Colorado. Part 1: Paraphyllothoxylon utahense. Great Basin Nat 43: 394--402.

van Gelder HA, Poorter L, Sterck FJ. 2006. Wood mechanics, allometry, and life-history variation in a tropical rain forest tree community. New Phytologist 171: 367--378.

Villéger S, Mason NWH, Mouillot D. 2008. New multidimensional functional diversity indices for a multifaceted framework in functional ecology. Ecology 89: 2290--2301.

Weiher E, Keddy PA. 1999. Ecological assembly rules: perspectives, advances, retreats. Cambridge University Press, Cambridge, UK.

Weiher E, Clarke GDP, Keddy PA. 1998. Community assembly rules, morphological dispersion, and the coexistence of plant species. Oikos 81: 309--322.

Wiemann MC, Wheeler EA, Manchester S, Portier KM. 1998. Dicotyledonous wood anatomical characters as predictor of climates. Palaeogeogr. Palaeoclimatol. Palaeoecol. 139: 83-100.

Wiemann MC, Manchester S, Wheeler EA. 1999. Paleotemperature estimation from dicotyledonous wood anatomical characters. Palaios 14: 459-474.

Wing SL, Boucher LD. 1998. Ecological aspects of the Cretaceous flowering plant radiation. 
447 Wheeler EA, Baas P. 1991. A survey of the fossil record for dicotyledonous wood and its

449 Wheeler EA, Lehman TM. 2009. New Late Cretaceous and Paleocene dicot woods of Big Bend

$450 \quad$ National Park, Texas and review of Cretaceous wood characteristics. IAWA J 30: 293--

451318.

452 Wheeler EA, Baas P. 2018. Wood evolution: Baileyan trends and Functional traits in the fossil record. IAWA J 2--42.

454 Zanne, AE, Westoby M, Falster DS, Ackerly DD, Loarie SR, Arnold EJS, Coomes D. 2010. Angiosperm wood structure: global patterns in vessel anatomy and their relation to wood density and potential conductivity. Am. J. Bot. 97: 207--215.

457

$458 \quad$ Figure legends

459 Figure 1. Location map of the El Cien Formation wood flora.

460

461 Figure 2. Pair-wise correlations of climate variables with functional richness (Fig. 2 A-C) and

462 functional dispersion (Fig. 2D-2F).

463

464 Figure 3. Bargraphs showing functional richness (A) and functional diversity (B) values in extant 465 communities and El Cien Formation wood flora. 
467 Figure 4. Bubble plots showing the relationship between AI and MAT. The size of the circles

468 represents A) functional richness (FRic) and B) functional dispersion (Fdis). As the relationship

469 of AI and MAP is high, MAP plot is not included.

470

471 Figure 5. 3D Scatter plot of the three climate variables correlated with functional diversity (MAT,

472 MAP and AI) and convex hull volumes for the communities studied. The colors of the circles

473 indicate the magnitude of the FRic, larger in dark blue, smaller in light yellow. Convex hulls

474 indicate the three-dimensional space occupied by all the species in each community; it is a

475 representation of the hydraulic niche. For simplicity, only $\mathrm{x}(F \log )$ and y axes $(S \log )$ are

476 portrayed, the z-axis $\left(K_{s} \log \right)$ was not drawn, but the convex hull are three-dimensional. 
491 Table 1. Extant communities and climate variables included in the study.

492

493

\begin{tabular}{|c|c|c|c|c|c|}
\hline Vegetation type & Locality & MAP (mm) & AI & PET $(\mathrm{mm})$ & MAT $\left({ }^{\circ} \mathrm{C}\right.$ \\
\hline jemi-deciduous forest & Chamela, Mexico & 798 & 0.47 & 1688 & 2 \\
\hline 'ropical rain forest & Manaus, Brazil & 2286 & 2.82 & 812 & 2 \\
\hline 1ontane forest & Ocuilán, Mexico & 1312 & 0.94 & 1400 & 1 \\
\hline -ropical rain forest & Porto Velho, Brazil & 2170 & 2.74 & 793 & \\
\hline -ropical rain forest & Tafelberg, Suriname & 2500 & 3.32 & 754 & \\
\hline 'ropical rain forest & Los Tuxtlas, Mexico & 4556 & 4.45 & 1024 & 2 \\
\hline tardwood forest & Coweeta, USA & 1850 & 2.06 & 900 & 1 \\
\hline 1esquite savanna & Cruz de Piedra, Argentina & 680 & 0.59 & 1149 & 1 \\
\hline Jesert scrub & Desert Center, CA, USA & 100 & 0.06 & 1585 & 2 \\
\hline )esert scrub & La Tranca, Mendoza, Argentina & 250 & 0.22 & 1141 & 1 \\
\hline 'alm forest & Entre Rios, Argentina & 1190 & 1.21 & 981 & 1 \\
\hline jage scrub & Tucker, CA, USA & 325 & 0.28 & 1143 & 1 \\
\hline tardwood forest & Whitehall, GA, USA & 1250 & 1.23 & 1018 & 1 \\
\hline 1esquite savanna & Copper Breaks, TX, USA & 663 & 0.46 & 1450 & 1 \\
\hline
\end{tabular}




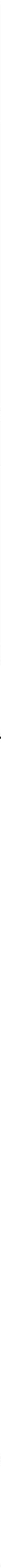


bioRxiv preprint doi: https://doi.org/10.1101/768283; this version posted September 14, 2019. The copyright holder for this preprint (which was not certified by peer review) is the author/funder, who has granted bioRxiv a license to display the preprint in perpetuity. It is made available under aCC-BY-NC-ND 4.0 International license.

Functional richness

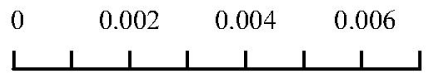

Hardwood forest (NC)

Desert scrub (CA)

Sage scrub (CA)

Mesquite savanna (TX)

Mesquite savanna (ARG)

Palm forest (ARG)

Hardwood forest (GA)

Desert scrub (ARG)

Montane forest (MEX)

Tropical rainforest (BRA)

Tropical rainforest (SUR)

Tropical rainforest (BRA)

El Cien

Semi-deciduous forest (MEX)

Tropical rainforest (MEX)
Functional dispersion

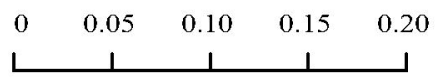

Desert scrub (CA)

Sage scrub (CA)

Mesquite savanna (TX)

Palm forest (ARG)

Hardwood forest (NC)

Mesquite savanna (ARG)

Desert scrub (ARG)

Montane forest (MEX)

Hardwood forest (GA)

Tropical rainforest (SUR)

Tropical rainforest (BRA)

Tropical rainforest (BRA)
$\mathrm{B}$
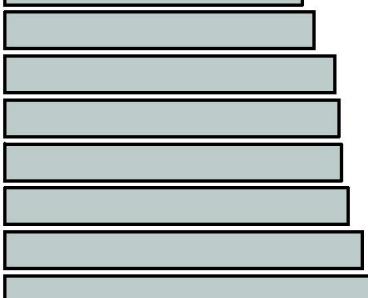

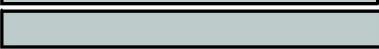

Semi-deciduous forest (MEX)

Tropical rainforest (MEX)

Tropical rainforest (MEX)
El Cien

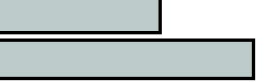


bioRxiv preprint doi: https://doi.org/10.1101/768283; this version posted September 14,2019 . The copyright holder for this preprint (which was not certified by peer review) is the author/funder, who has granted bioRxiv a license to display the preprint in perpetuity. It is made available under aCC-BY-NC-ND 4.0 International license.

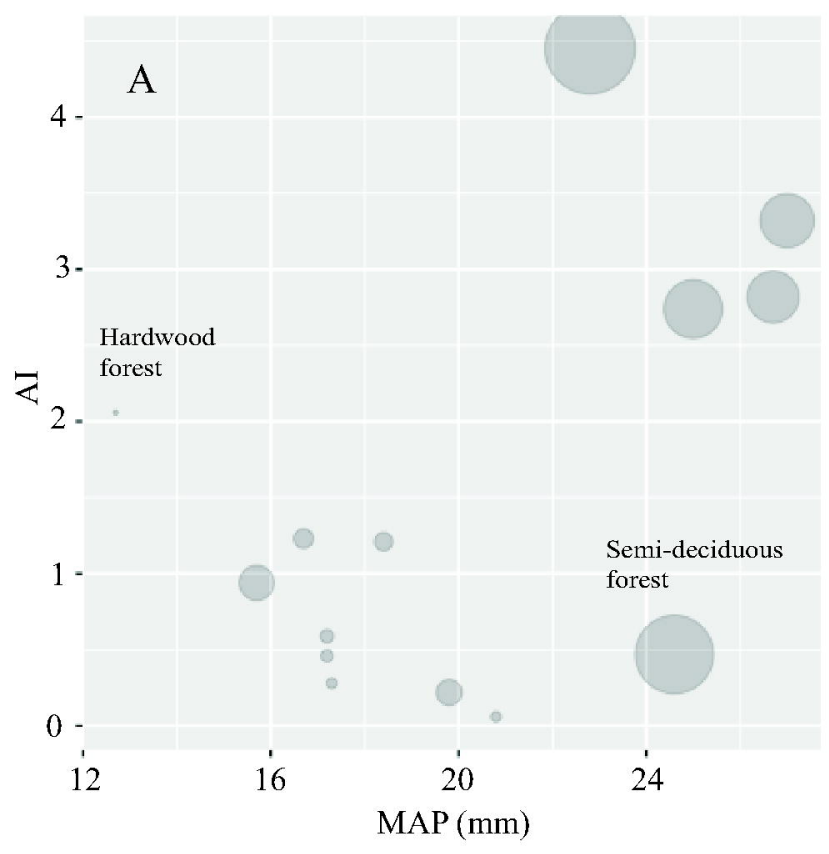

FRic
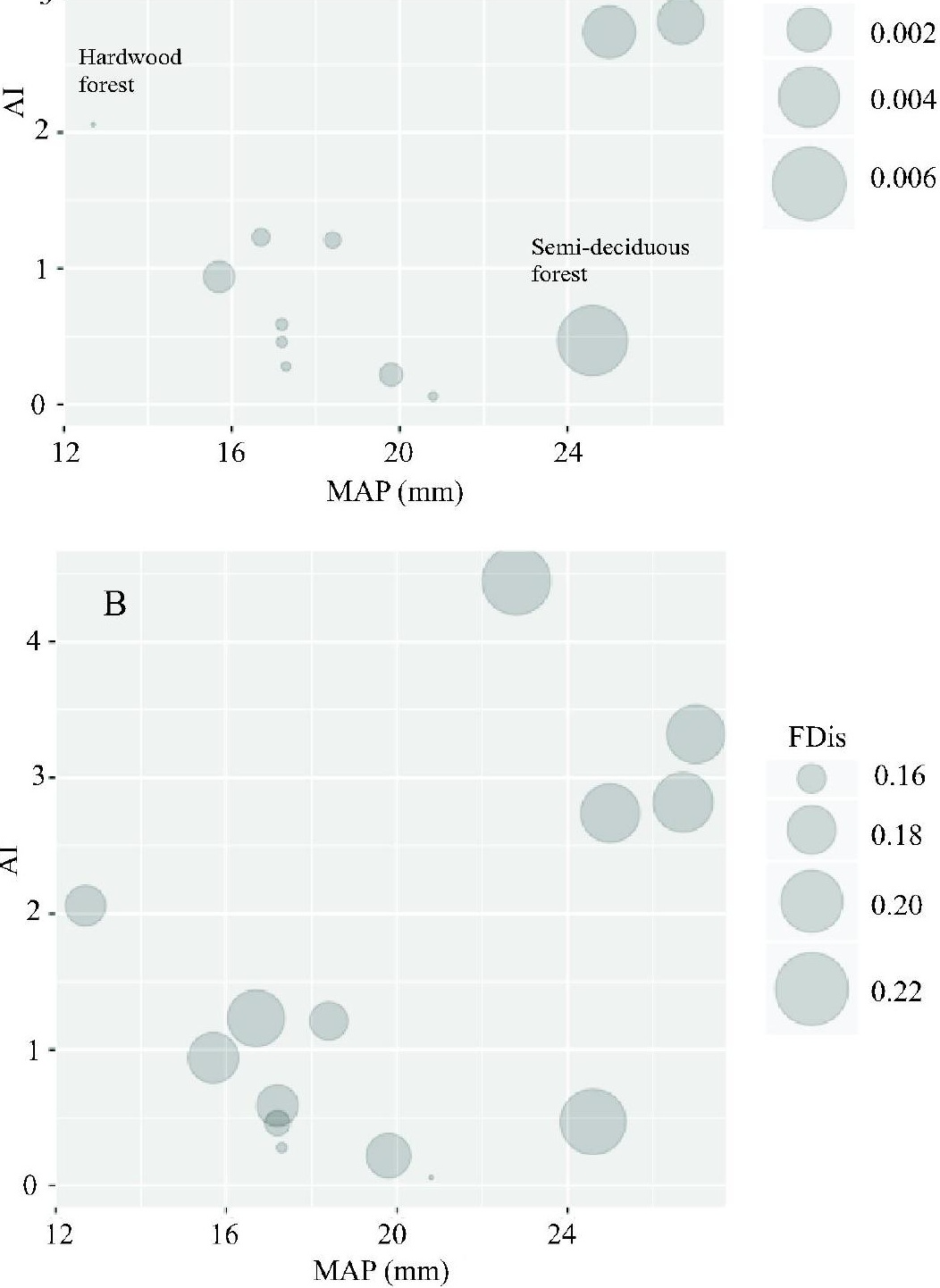
